\title{
AS CATEGORIAS CONHECIMENTO E PROCESSOS DE PERFETTI NA LEITURA EM LÍNGUA MATERNA: UM EXPERIMENTO
}

Alessandra Baldo*

Resumo: Perfetti et al. (1996) dividem em duas grandes categorias os componentes presentes na compreensão leitora: a de processos e a de conhecimento. $\mathrm{Na}$ primeira, estão os processos lexicais, a capacidade da memória de trabalho, a realização de inferências e o monitoramento da compreensão; na segunda, o significado das palavras e o conhecimento de domínio. O presente artigo tem como objetivos mostrar a importância dos tipos de conhecimento implicados na segunda categoria para o processo global de compreensão leitora, como também a interdependência entre as duas categorias. Para tanto, foi realizada uma comparação entre as estratégias utilizadas por oito leitores adultos ao responderem a questões específicas de inferência de vocabulário, a partir da aplicação de um teste de compreensão leitora em língua materna pela técnica dos protocolos verbais. Com base nos escores obtidos, os participantes foram divididos em dois grupos distintos de proficiência em leitura. A análise veio a corroborar a intrínseca relação entre significado de palavras e conhecimento de domínio nos processos de compreensão leitora, em especial de inferência lexical.

Palavras-chave: compreensão; estratégia de leitura; conhecimento; significado de palavra; inferência lexical.

\section{INTRODUÇÃO}

Com base na nossa experiência como leitores, sabemos que, sem o conhecimento do significado das palavras presentes nos textos, o processo de compreensão sequer inicia. Ainda que outros fatores estejam implicados, o conhecimento de vocabulário tem um caráter único na

* Professora da Universidade Federal de Pelotas. Doutora em Lingüística Aplicada. E-mail: $<$ lelabaldo@terra.com.br>. 


\section{0}

medida em que é o responsável pelo desencadeamento de outros processos específicos - por exemplo, a realização de inferências e o monitoramento da compreensão.

Demonstrando a procedência dessa afirmação, uma análise de resultados de pesquisas mostrou que o conhecimento das palavras aparece como um preditor mais refinado de compreensão do que a habilidade de realizar inferências e de identificar as idéias principais (ANDERSON; FREEBODY, 1981). Além disso, vários autores têm mostrado, especialmente com relação à aprendizagem de língua estrangeira, que um aprimoramento na leitura pode ser atribuído a um aumento de vocabulário (BECK; PERFETTI; McKEOWN, 1982; STAHL, 1983; COADY et al., 1993; GRABE; STOLLER, 1997).

A familiaridade com as palavras, no entanto, não é o único tipo de conhecimento necessário durante a leitura. Resgatando novamente nossa experiência como leitores, sabemos que, ao ativarmos o significado de determinadas palavras, ativamos também um conhecimento mais geral, comumente denominado, na literatura, enciclopédico ou prévio. Porque a leitura não ocorre em um vácuo - sendo ela um evento de linguagem, e o texto, assim, pertencendo a um determinado gênero textual -, a importância desse tipo de conhecimento para o processo de leitura torna-se evidente.

Como esses dois tipos de conhecimento são indissociáveis, neste artigo procuramos ilustrar essa inter-relação com base na teoria de Perfetti et al. (1996), a partir das estratégias utilizadas por oito leitores adultos, divididos em níveis distintos de proficiência em leitura, para responder a itens de inferência lexical presentes em um teste de compreensão leitora.

A principal razão para a escolha desta teoria como suporte para nosso estudo está no fato de ela dar conta da integração entre o conhecimento de palavras e o conhecimento prévio, como será detalhando na seção seguinte. ${ }^{1}$

\footnotetext{
${ }^{1}$ Em Perfetti et al. (1996), o conhecimento prévio é denominado conhecimento de domínio (ver seção 1).
}

BALDO - As categorias conhecimento e... 


\section{O CONHECIMENTO COMO COMPONENTE DA COM- PREENSÃO LEITORA}

Tudo o que pode ser identificado como um componente do processo de compreensão leitora também pode ser identificado como causador de falha nesse processo. Foi essa a conclusão à qual Perfetti et al. (1996) chegaram com base no baixo desempenho em leitura de três dos quatro universitários que forneceram os dados para a realização de seu estudo. Assim, além dos já reconhecidos (i) processos lexicais e (ii) capacidade limitada da memória de trabalho, os autores identificaram outras causas de dificuldades de leitura. ${ }^{2}$ A lista expandida prevê também a (iii) realização de inferências e o (iv) monitoramento da compreensão, componentes agrupados juntamente com os dois anteriores na categoria de processos, e ainda o (v) significado das palavras e o (vi) conhecimento de domínio, estes dois últimos previstos na categoria de conhecimento.

Mesmo pertencendo a categorias distintas, cada um desses componentes se inter-relaciona. Os autores se valem do funcionamento da estratégia de monitoramento para ilustrar isso: enquanto o automonitoramento está diretamente relacionado à representação que o leitor faz do texto, essa representação, por sua vez, é dependente da adequação das inferências construídas por ele à medida que processa a informação textual.

Com relação à categoria conhecimento, os autores apontam que a literatura muitas vezes deixa perpassar certo desconforto ao tratar do tema, transmitindo a idéia de que seria bem mais simples investigar os processos de compreensão leitora sem ela. Perfetti et al. (1996) reconhecem que talvez o papel desempenhado pelo conhecimento no "desencadeamento de processos importantes para a compreensão" tenha sido negligenciado, especialmente "o conhecimento necessário para controlar ações como o monitoramento da compreensão e a geração de inferências" (1996, p. 147).

A opção por separar o conhecimento de palavras em uma categoria distinta da atribuída aos processos lexicais pode ser entendida

\footnotetext{
2 Perfetti (1985), no estudo que cunhou de "Teoria da Eficiência Verbal", havia identificado os processos lexicais e a capacidade limitada da memória de trabalho como as duas fontes principais de falha na compreensão leitora.
} 
como um esforço para acabar com essa possível negligência, considerando-se que a justificativa para fazê-lo está calcada em dois princípios dificilmente discutíveis: (i) problemas em entender as palavras no texto causarão problemas no entendimento do texto; (ii) embora os leitores possam inferir o significado das palavras, há um limite para a utilidade dessa estratégia.

Perfetti et al. definem o conhecimento de domínio como "conceitos que são parte do background de qualquer texto" (1996, p. 142). Esclarecem que este tem um papel crítico na construção de uma representação adequada do texto, na medida em que é ele que possibilita a relação entre a representação lingüística que o leitor faz do material lido e a representação da situação baseada em inferências mais complexas. Por fim, os autores enfatizam que tanto o conhecimento de palavras como o conhecimento de domínio estão intimamente relacionados, já que os conceitos em um domínio específico são expressos por meio de um vocabulário específico.

Antes de passarmos para a seção seguinte, cabe ainda retomar uma das justificativas dos autores para colocar o conhecimento das palavras em uma categoria distinta da atribuída aos processos lexicais ou seja, as limitações da estratégia de inferir o significado das palavras pelo contexto -, já que ela não parece ser consensual.

Esta falta de consenso pode ser atestada em Nation e Meara (2000), ao advogarem que, entre as quatro estratégias mais eficazes para auxiliar a encontrar o significado de palavras desconhecidas e a fixá-las na memória, a utilização dos indícios contextuais está entre a mais útil. Ainda que os autores sejam cautelosos ao afirmarem que "para aprender a estratégia e utilizá-la corretamente, os leitores precisam conhecer entre 95-98\% das palavras de um texto, ou seja, a palavra a ser aprendida deve estar embasada em contexto compreensível" (p. 44), eles entendem que a maioria dos contextos fornece informação suficiente para que as palavras desconhecidas sejam compreendidas.

Essa visão não é, no entanto, compartilhada integralmente por Laufer (1997) e Nassaji (2003). ${ }^{3}$ Mesmo não contestando o valor da

\footnotetext{
3 Embora esses dois autores investiguem a aquisição de vocabulário na língua estrangeira, entendemos que suas colocações são pertinentes também para a aquisição de vocabulário na língua materna, e por isso as incluímos aqui.
}

BALDO - As categorias conhecimento e... 
inferência lexical pelo contexto, nem o fato de ela ocorrer, Laufer (1997) entende que é importante colocá-la em uma perspectiva apropriada, já que há inúmeros fatores que interferem na sua utilização bem-sucedida, como, por exemplo, indícios contextuais inexistentes, não aproveitáveis ou parciais. Nesse sentido, os achados do estudo de Nassaji (2003), ao investigar em que medida leitores de nível intermediário de inglês como segunda língua conseguiam inferir novas palavras pelo contexto, dão força à colocação de Laufer (1997). De acordo com a análise feita pelo autor, os aprendizes demonstraram dificuldades em inferir os significados das palavras desconhecidas pelo contexto, mesmo conhecendo a maioria das palavras do texto lido, resultado que corroboraria o resultado de outros estudos, "tanto na língua materna como na língua estrangeira, que mostraram que a inferência de palavras novas pelo contexto não é uma tarefa fácil” (NASSAJI, 2003, p. 663).

Levando-se em conta essa interdependência entre conhecimento lexical, contexto e inferência, na seção seguinte avaliaremos a importância da categoria conhecimento proposta por Perfetti et al. (1996) para a compreensão leitora, como também a relação intrínseca desta com a categoria de processos, a partir da análise das estratégias empregadas por oito leitores adultos em questões de inferência de vocabulário. Esses leitores foram divididos em dois grupos, de acordo com seu nível de proficiência em leitura. O primeiro grupo foi constituído dos quatro sujeitos com escores mais altos de compreensão leitora, e o segundo, dos quatro sujeitos com escores mais baixos, selecionados de um estudo que contou com 20 participantes (BALDO, 2006). ${ }^{4}$

\section{METODOLOGIA}

A pesquisa da qual provêm os dados para esse artigo teve como sujeitos 20 alunos do Programa de Pós-Graduação em Letras de uma instituição de ensino superior do Rio Grande do Sul.

\footnotetext{
4 Trata-se da tese de Doutorado da autora (ver referências), cujos dados e metodologia estão reenfocados aqui para o tratamento das questões específicas discutidas neste artigo.
} 
Para o teste de compreensão leitora, foi selecionado um texto da edição de 02.10 .2002 da revista Veja, intitulado "1.200.000 espectadores..." (Anexo A), com base no qual foi elaborado um questionário com doze questões. O texto, sobre o filme Cidade de Deus, possui três partes principais: a primeira focaliza o sucesso de bilheteria, com uma tentativa de explicação para isso; a segunda remete às críticas recebidas pelo filme; a terceira traz um histórico e os planos profissionais do diretor, Fernando Meirelles.

Das doze questões do teste, quatro delas foram reservadas para investigar a inferência de vocabulário, conforme pode ser visualizado no Quadro 1. As quatro palavras selecionadas, cada uma delas equivalendo a uma questão, foram as seguintes: sinistra, na linha 17; zelo linha-dura, na linha 19; apartheid social brasileiro, na linha 22; veladamente, na linha 27.

\begin{tabular}{|l|l|}
\hline Questões & Operações Cognitivas \\
\hline Questão 1 & Síntese assunto principal \\
\hline Questões 2 e 3 & Inferência \\
\hline Questões 4, 5, 6, 7 e 8 & $\begin{array}{l}\text { Identificação da informação explícita ou } \\
\text { em paráfrase }\end{array}$ \\
\hline Questões 9a, 9b, 9c e 9d & Inferência de vocabulário \\
\hline
\end{tabular}

Quadro 1 - Operações cognitivas previstas para cada questão.

Os sujeitos liam silenciosamente o texto, e após forneciam respostas orais ao questionário, por meio da técnica dos protocolos verbais, para a qual haviam sido previamente testados. As respostas eram gravadas em áudio e transcritas e, com base na transcrição dos dados, a pesquisadora inferia as estratégias de leitura utilizadas para resolver cada uma das questões propostas, como também avaliava a compatibilidade das respostas com as informações apresentadas no texto, conforme avaliação prévia de dois especialistas em língua portuguesa.

Foram descritos três níveis de adequação de respostas totalmente adequado (TA), parcialmente adequado (PA) e inadequado (I). Cada questão valia 2 pontos. Assim, se uma resposta fosse considerada totalmente adequada, o escore seria 2; se parcialmente adequada, 1; se inadequada, 0 . Como havia 12 questões, o escore 
máximo que cada participante poderia alcançar seria 24. Para nossos objetivos de pesquisa, foram invalidados os dados dos sujeitos que não alcançaram pelo menos 12 pontos, ou seja, $50 \%$ das respostas corretas.

Uma lista com 23 estratégias de leitura foi utilizada para a decodificação dos dados presentes nos protocolos. Esse material foi elaborado a partir do estudo de Anderson (1991), mas adaptado para contemplar as informações verificadas nos protocolos verbais.

\section{DESCRIÇÃO DOS DADOS}

Como já mencionado, os oito sujeitos foram divididos em dois grupos, de acordo com os escores obtidos no teste de leitura. O primeiro grupo, dos sujeitos com escores mais altos de compreensão, constitui-se dos sujeitos 5, 10, 16 e 19, conforme apresentado na Tabela 1, e o segundo, dos sujeitos com escores mais baixos, dos sujeitos 1, 6, 9 e 17, conforme descrito na Tabela 2.

Tabela 1 - Sujeitos com escores mais altos de compreensão leitora:

\begin{tabular}{l|l}
\hline Sujeitos & Escores \\
\hline Sujeito 5 & 23 \\
\hline Sujeito 10 & 22 \\
\hline Sujeito 16 & 21 \\
\hline Sujeito 19 & 24 \\
\hline
\end{tabular}

Tabela 2 - Sujeitos com escores mais baixos de compreensão leitora:

\begin{tabular}{l|l}
\hline Sujeitos & Escores \\
\hline Sujeito 1 & 15 \\
\hline Sujeito 6 & 15 \\
\hline Sujeito 9 & 15 \\
\hline Sujeito 17 & 14 \\
\hline
\end{tabular}

As estratégias de leitura empregadas pelos oito participantes aqui observados encontram-se discriminadas nas Tabelas 3 e 4. A primeira contém os dados dos sujeitos com desempenho mais satisfatório em 
compreensão leitora, e a segunda, os dados dos sujeitos com desempenho menos satisfatório. Como essas estratégias estão identificadas por um número, a fim de possibilitar a análise, elas encontram-se legendadas do seguinte modo:

Estratégia 01: Recuperação da informação presente na memória;

Estratégia 06: Retorno ao texto para confirmar uma resposta previamente formulada;

Estratégia 10: Recorrência ao conhecimento extratextual; 5

Estratégia 11: Releitura da frase/parágrafo no qual a palavra/expressão está inserida;

Estratégia 14: Repetição de parte ou de toda a questão;

Estratégia 15: Uso de entonação tipo canto para facilitar a compreensão;

Estratégia 20: Comentários para mostrar a dificuldade de entender e/ou responder à questão;

Tabela 3 - Estratégias utilizadas nas questões de inferência de vocabulário pelos sujeitos com escores mais altos de compreensão:

\begin{tabular}{|l|l|l|l|l|}
\hline \multirow{2}{*}{ Sujeitos } & \multicolumn{4}{|l|}{ Estratégias utilizadas } \\
\cline { 2 - 5 } & Questão 9a & Questão 9b & Questão 9c & Questão 9d \\
\hline Sujeito 5 & Est.11 & Est.11 & Est.11,10 & Est.1 \\
\hline Sujeito 10 & Est.11 & Est.11 & Est.11,10 & Est.11 \\
\hline Sujeito 16 & Est.1,6 & Est.11 & Est.10 & Est.1, 6 \\
\hline Sujeito 19 & Est.15,11 & Est.1,11,6 & Est.1,6 & Est.1,11,6 \\
\hline
\end{tabular}

\footnotetext{
${ }^{5}$ Embora reconheçamos que a linha divisória entre a estratégia n. 1, "recuperação da informação presente na memória", e a n. 10, "recorrência ao conhecimento extratextual", seja muito tênue, já que ambas tratam de recuperação de informação na memória, utilizamos o seguinte critério: quando o leitor recuperava informações presentes explicitamente no texto, entendíamos que se tratava da estratégia n. 1; quando ele recorria ao conhecimento extratextual para fazer inferências e associações a partir da base textual, inferíamos que se tratava da n. 10 .
}

BALDO - As categorias conhecimento e... 
Tabela 4 - Estratégias utilizadas nas questões de inferência de vocabulário pelos sujeitos com escores mais baixos de compreensão:

\begin{tabular}{|l|l|l|l|l|}
\hline \multirow{2}{*}{ Sujeitos } & \multicolumn{3}{|l|}{ Estratégias utilizadas } \\
\cline { 2 - 5 } & Questão 9a & Questão 9b & Questão 9c & Questão 9d \\
\hline Sujeito 1 & Est. 11,14,20 & Est.11 & Est.11,10 & Est.11 \\
\hline Sujeito 6 & Est.11 & Est.11 & Est.11/15 & Est.11/15,20,11 \\
\hline Sujeito 9 & Est.11 & Est.11 & Est.11,10 & Est.1 \\
\hline Sujeito 17 & Est.11 & Est.11 & Est.11,10 & Est.11 \\
\hline
\end{tabular}

A fim de ser possível uma melhor visualização da freqüência de uso de cada uma das estratégias em questão pelos dois grupos de leitores, esses dados estão dispostos na Tabela 5.

Tabela 5 - Freqüência de uso das estratégias pelos leitores com escores mais altos e com escores mais baixos de compreensão:

\begin{tabular}{|c|c|c|c|}
\hline \multirow[t]{2}{*}{ Estratégias } & \multicolumn{3}{|c|}{ Freqüência de uso de estratégias } \\
\hline & $\begin{array}{lr}\begin{array}{l}\text { Leitores } \\
\text { escores }\end{array} & \text { mai } \\
\text { altos } & \\
\end{array}$ & \begin{tabular}{|l} 
Leitores \\
escores \\
baixos
\end{tabular} & $\begin{array}{l}\text { com } \\
\text { mais }\end{array}$ \\
\hline $\begin{array}{l}\text { 1: Recuperação da informação sobre } \\
\text { o texto presente na memória }\end{array}$ & & & 1 \\
\hline $\begin{array}{l}\text { 6: Retorno ao texto para confirmar } \\
\text { uma resposta }\end{array}$ & & & 0 \\
\hline $\begin{array}{l}\text { 10: Recorrência ao conhecimento } \\
\text { extratextual }\end{array}$ & & & 3 \\
\hline 11: Releitura da frase/parágrafo & 1 & & 16 \\
\hline $\begin{array}{l}\text { 14: Repetição de parte ou de toda a } \\
\text { questão }\end{array}$ & & & 1 \\
\hline $\begin{array}{l}\text { 15: Uso de entonação tipo canto para } \\
\text { facilitar a compreensão }\end{array}$ & & & 1 \\
\hline $\begin{array}{l}\text { 20: comentários relativos à } \\
\text { dificuldade de entender e/ou } \\
\text { responder à questão }\end{array}$ & & & 2 \\
\hline
\end{tabular}




\section{ANÁLISE DOS DADOS}

Um primeiro olhar para os dados agrupados na Tabela 5 é de grande utilidade para auxiliar no encaminhamento dos temas levantados neste artigo, ou seja, a relevância da categoria conhecimento para a compreensão leitora, bem como a indissociável relação entre esta e a categoria de processos, de acordo com Perfetti et al. (1996). Como havíamos colocado inicialmente, o objetivo aqui é ilustrar a procedência da teoria dos autores com base em uma comparação das estratégias utilizadas por sujeitos mais proficientes e menos proficientes em leitura.

Começando com uma subversão da ordem, as estratégias de n. 20, "comentários para mostrar a dificuldade de entender e/ou responder à questão", n. 15, "uso de entonação tipo canto para facilitar a compreensão", e n. 14, "repetição de parte ou de toda a questão", não parecem carecer de uma análise mais detalhada, dada a pouca utilização dessas pelos sujeitos. Se algo pode ser dito, é que seria esperado que o emprego da estratégia n. 20 ("comentários para mostrar a dificuldade de entender e/ou responder à questão") aparecesse somente entre os sujeitos com escores mais baixos, o que se confirmou.

Com relação à estratégia n.10, "recorrência ao conhecimento extratextual", houve exatamente o mesmo número de ocorrências entre os dois grupos de leitores. Vale notar ainda que o número de ocorrências é pouco expressivo, mesmo para um grupo pequeno. Já para a estratégia mais empregada pelos dois grupos de leitores, a de n. 11, "releitura da frase/parágrafo no qual a palavra/expressão está inserida", pode-se perceber que houve um número maior de ocorrências entre os leitores considerados menos proficientes - dezesseis ocorrências, em comparação a onze, no outro grupo. Como veremos a seguir, isso se explica pelo fato de que os leitores mais proficientes conseguiram utilizar as estratégias n.1, "recuperação de informação sobre o texto presente na memória", e n. 6, "retorno ao texto para confirmar uma resposta previamente formulada", mais freqüentemente do que os menos proficientes, substituindo-a então pela estratégia n. 11, de "releitura da frase/parágrafo em que a palavra/expressão se encontrava".

Esses dados constituem-se nos mais interessantes para nossos objetivos, em particular os advindos da freqüência de uso das estratégias n. 1, "recuperação da informação sobre o texto presente na memória", e 
n. 6, "retorno ao texto para confirmar uma resposta previamente formulada". Em termos proporcionais, encontramos aqui a maior diferença entre os dois grupos de leitores: enquanto os sujeitos considerados mais proficientes utilizam cinco vezes a estratégia n. 1 , os menos proficientes a utilizam somente uma vez. Situação análoga é encontrada para a estratégia n. 6: os sujeitos com escores mais altos se valem dela cinco vezes para realizarem as inferências de vocabulário; os com escores mais baixos, nenhuma.

A utilização mais freqüente dessas estratégias pelos leitores mais proficientes poderia sugerir que eles já possuíam algum tipo de conhecimento sobre o vocábulo, especialmente com relação ao uso da estratégia n. 1, "recuperação da informação sobre o texto presente na memória". Naturalmente, ao resgatarem a informação sobre o texto, os sujeitos também resgatavam saberes prévios, já que muitas das idéias e conceitos apresentados no material lido somente poderiam ter sido gravados pelos leitores devido ao que Perfetti et al. (1996) denominaram de conhecimento de domínio. Se os leitores não o possuíssem, poder-seia argumentar, não haveria como iniciar o processo de inferência lexical.

A utilização da estratégia n. 6, "retorno ao texto para confirmar uma resposta previamente formulada", pode ser vista, neste contexto, como uma etapa deste processo de inferência lexical iniciado pela recuperação da informação presente na memória (estratégia n. 1). Assim, se observarmos, por exemplo, o comportamento cognitivo via estratégias de leitura dos sujeitos 16 (questões 9a e 9d) e 19 (questões 9b, 9c e 9d), demonstrado na Tabela 3, podemos notar que a inferência da palavra/expressão iniciou pela ativação na memória da informação sobre o texto lido, e finalizou com um retorno ao texto para confirmar a procedência dessa ativação.

Para ilustrar mais claramente esse processo, analisaremos os protocolos verbais dos Sujeitos 16 e 19 ao formularem respostas a duas questões de inferência de vocabulário. No primeiro caso, temos a resposta ao significado do advérbio "veladamente"; no segundo caso, ao significado da expressão "apartheid social brasileiro". As informações entre parênteses registram as observações que a entrevistadora fez durante a sessão de coleta de dados, bem como as interações verbais mantidas com os participantes. As reticências servem para mostrar uma 
pausa na fala do sujeito - devida, provavelmente, a uma reflexão sobre seu processo de compreensão.

\section{[Sujeito 16 - Questão 9d]}

Palavra: veladamente

Resposta: veladamente deve ser uma coisa que não é explícita, né, não sei se é isso (volta ao texto e relê em silêncio a parte na qual a expressão se encontra), ele é veladamente acusado..., é, não é uma coisa explícita, é uma coisa velada, uma coisa implícita.

Estratégia(s) empregada(s): n.1, recuperação da informação sobre o texto presente na memória; n. 6, retorno ao texto para confirmar uma resposta previamente formulada.

\section{[Sujeito 19 - Questão 9c]}

Expressão: apartheid social brasileiro

Resposta: diferenças sociais do país, na linha 22 (volta rapidamente ao texto e relê em silêncio parte do segmento do texto em que a expressão está inserida), é, as diferenças sociais no Brasil.

(Entrevistadora: Já tinha visto essa expressão?)

Nessa expressão não lembro de ter visto, só apartheid.

Estratégia(s) empregada(s): n. 1, recuperação da informação sobre o texto presente na memória; n. 6, retorno ao texto para confirmar uma resposta previamente formulada.

Uma análise desses dois excertos de protocolos nos possibilita perceber mais claramente a importância do conhecimento para o processo de compreensão leitora - e mais especificamente aqui, para a realização de inferências vocabulares. Embora o Sujeito 16 explicite não ter certeza sobre o significado exato da palavra - "deve ser uma coisa que não é explícita, né, não sei se é isso" -, ele mostra que possui uma idéia a respeito de um possível significado, construída, provavelmente, ao longo de sua vida de leitor. A partir desse conhecimento inicial é que volta ao texto para confirmar - ou não - sua idéia, o que, de acordo com sua hipótese, acontece de fato. Procedimento semelhante é verificado com base nas informações do Sujeito 19: ainda que a resposta direta ao significado da expressão leve a crer que ele já a conhecia previamente à leitura do texto - hipótese que é desconfirmada pelo próprio sujeito -,

BALDO - As categorias conhecimento e... 
sabe-se que ele conhece o significado de apartheid. Assim, resgatando as informações do texto, o que necessariamente significava o resgate de informações de domínios específicos de conhecimento, ele consegue inferir o significado da expressão.

Por outro lado, mencionamos anteriormente que, caso os leitores não possuíssem o conhecimento de domínio adequado para recuperar as informações presentes no texto, poderia haver uma falha no processo de inferência lexical, já que não haveria como empregar a estratégia n. 1, "recuperação da informação presente na memória", para dar início ao processo de inferência. Comentamos, ainda, que os leitores com escores mais baixos, por não terem à disposição a estratégia n. 1, necessitavam primeiramente reler a frase/parágrafo no qual a palavra/expressão se encontrava, o que explicaria o uso mais freqüente da estratégia n. 11 (releitura da frase/parágrafo no qual a palavra/expressão está inserida). Para demonstrar isso, apresentaremos a seguir os protocolos verbais dos Sujeitos 1 e 9, com os mesmos itens lexicais utilizados para os dois sujeitos do grupo mais proficiente em leitura, ou seja, o advérbio "veladamente" e a expressão "apartheid social brasileiro". Para facilitar a compreensão, a parte que foi relida pelos sujeitos está italicizada.

\section{[Sujeito 1 - Questão 9d]}

Palavra: veladamente

Protocolo verbal: Veladamente: vou ler (retorna ao texto e procura pela informação), sempre que um diretor vem do meio publicitário, caso de Salles, Meirelles e Andrucha, ele é veladamente acusado de usar sen arsenal... Veladamente aqui é no sentido de que é certo de que ele vai ser acusado, certamente ele vai ser acusado disso. Pela frase, é isso.

Estratégia(s) empregada(s): n. 11, releitura da frase/parágrafo em que a palavra/expressão se encontra.

\section{[Sujeito 9- Questão 9c]}

Expressão: apartheid social brasileiro

Protocolo verbal: apartheid social brasileiro, linha 22. Cidade de Deus aprofundou a discussão sobre o apartheid social brasileiro e virou matéria urgente. Ah, apartheid social brasileiro, comparando com o apartheid da África, imagino, querendo, né, mostrar, sei eu, ah, de 
novo, tirar alguma coisa de positivo de uma coisa tão violenta, que eram, por exemplo, as cenas na Cidade de Deus, ou o mundo em que vivem os protagonistas de Cidade de Deus. Apartheid social brasileiro, me parece uma coisa até meio irônico assim, Cidade de Deus aprofundou a discussão sobre o apartheid social brasileiro. Mas não é irônico, porque a mulher aqui, a escritora, só coloca o Fernando Meirelles pra cima. Eu acho que tá comparando com o apartheid africano e essa busca dos programas sociais brasileiros como uma coisa que tá na moda, que tá em voga.

(Entrevistadora: Já conhecias essa expressão antes?)

Sim, o apartheid.

(Entrevistadora: Mas a expressão toda, apartheid social brasileiro?)

Não, nunca tinha visto.

Estratégia(s) empregada(s): n. 11, releitura da frase/parágrafo em que a palavra/expressão se encontra; n. 10, recorrência ao conhecimento extratextual.

Tanto o Sujeito 1 como o Sujeito 9 confirmam o uso mais freqüente da estratégia n. 11 por uma provável impossibilidade de construírem hipóteses sobre o significado das palavras/expressões a partir do resgate direto da memória das informações sobre o texto. ${ }^{6}$ No caso do Sujeito 1, essa falta de hipótese pode ter sido agravada por um contexto lingüístico pouco preciso. Aqui poderia entrar em cena a importância do conhecimento de domínio para a realização da inferência da palavra, já que, pode-se argumentar, se o leitor tivesse ativado o conhecimento de que "eticamente, não é correto criticar colegas de profissão - pelo menos não abertamente", ele poderia ter feito a

6 Contudo, essa indisponibilidade não significa necessariamente que não se consiga chegar ao significado das palavras/expressões de um texto, via realização de inferências, a partir da estratégia da releitura, o que implicaria ir contra robusta evidência de pesquisa. Se observarmos o comportamento dos Sujeitos 5 e 10, por exemplo, ilustrado na Tabela 3, observaremos que eles utilizaram preferencialmente a estratégia de n. 11, e esse movimento representou o início de uma tentativa bem-sucedida de inferência de significado. Nosso argumento aqui se refere a uma análise do comportamento desses leitores específicos.

BALDO - As categorias conhecimento e... 
inferência apropriada. ${ }^{7}$ Como esse conhecimento faltou, ou pelo menos não foi ativado, a inferência adequada também não aconteceu.

Já no caso do Sujeito 9, houve a tentativa de construção de uma hipótese para o significado da expressão a partir do resgate de conhecimento extratextual - o apartheid na África. No entanto, a associação entre o conhecimento extratextual do sujeito e as informações presentes no texto não resultou em uma inferência bem-sucedida. Embora o participante tivesse mencionado em sua resposta fatos como a violência, a questão social, o apartheid na África, parece ter faltado um melhor monitoramento de todos esses dados com a base de texto, e a conseqüência foi uma compreensão incompleta da expressão.

Um outro modo de explicar o insucesso desses leitores na tentativa de inferência lexical pode ser encontrado na afirmação de Laufer (1997) de que, embora o contexto muitas vezes forneça indícios para que os leitores depreendam o significado de palavras novas, mesmo assim ocorre falha no processo por eles não conseguirem empregar apropriadamente tais indícios.

Desse modo, temos aqui dois exemplos de como uma falha em construir uma inferência apropriada está relacionada a uma falha no processo de monitoramento da compreensão, e vice-versa, pois o modo mais eficaz que o leitor possui para rever o seu processo de monitoramento é o dar-se conta da procedência ou improcedência das inferências que constrói ao longo do processo de compreensão leitora. Assim, ainda que a inferência lexical esteja primeiramente ligada ao conhecimento de domínio, cabe relembrar que tanto o monitoramento da compreensão como a realização de inferências estão agrupados na primeira categoria de Perfetti et al. (1996), a de processos, o que ilustra a relação indissociável entre essas duas categorias.

\section{CONSIDERAÇÕES FINAIS}

No início deste artigo, sublinhamos como nossos objetivos mostrar a importância da categoria conhecimento para a compreensão

\footnotetext{
7 Isso porque naquela parte do texto estava sendo feito um comentário sobre as críticas que diretores de cinema com formação como publicitários - e não como cineastas propriamente ditos - recebem de outros colegas, de formação "clássica" (ver Anexo A).
} 


\section{4}

leitora, com também a interdependência desta com a categoria processos, de acordo com a classificação de Perfetti et al. (1996). Para tanto, esclarecemos que seria realizada uma comparação entre as estratégias utilizadas por leitores mais e menos proficientes, ao responderem a questões de inferência lexical presentes em um teste de leitura em língua materna.

Com base na análise dos dados, verificamos que a maior diferença entre os dois grupos de leitores, em termos de utilização de estratégias, resumiu-se à utilização mais freqüente, pelos leitores classificados como mais proficientes, das estratégias que previam algum tipo de conhecimento prévio com relação aos vocábulos - ainda que isso não significasse o conhecimento do significado do vocábulo previamente à leitura do texto, como foi ilustrado pela transcrição dos excertos de protocolos verbais. A principal falha na inferência lexical se deveu a problemas no monitoramento da compreensão, ocasionados, em grande parte, pela impossibilidade de utilizar os indícios contextuais disponibilizados pelo texto, um dos maiores obstáculos para a tentativa bem-sucedida de inferir vocábulos desconhecidos, de acordo com Laufer (1997).

Assim, tomamos esse achado de pesquisa como um indicativo da procedência da teoria da Perfetti et al. (1996), não somente com relação à relevância da categoria conhecimento para os processos de compreensão leitora, como também com relação à interdependência das duas categorias previstas pela teoria.

Antes de terminar esse artigo, é sempre importante lembrar a natureza qualitativa deste trabalho. Desse modo, ainda que entendamos que nosso objetivo primeiro tenha sido atingido, as reflexões aqui tecidas devem, naturalmente, ser interpretadas dentro dos limites impostos pelo estudo.

\section{REFERÊNCIAS}

ANDERSON, N. J. Individual differences in strategy use in second language reading and testing. The modern language journal, v. 75, p. 460-72, 1991. 
ANDERSON, R.C.; FREEBODY, P. Vocabulary and knowledge . In: GUTRIE, J. T. Comprehension and teaching: research review. Newark, DE: International Reading Association, 1981. p. 77-117.

BALDO, A. Estratégias de leitura em língua materna e em língua estrangeira. Tese (Doutorado em Lingǘstica e Letras) - Pontifícia Universidade Católica do Rio Grande do Sul, Porto Alegre, 2006.

BECK, I.L; PERFETTI, C.A; McKEOWN, M.G. Effects of text construction and instructional procedures for teaching word meanings on comprehension and recall. Journal of educational psychology, v. 74, p. 506-521, 1982.

BOSCOV, I. 1.200.000 espectadores... Veja, São Paulo: Abril Cultural, ano 35, n. 39, p.132-133, 10 Fev. 2002.

COADY, J. et al. High-frequency vocabulary and reading proficiency in ESL readers. In: HUCKIN, T.; HAYNES, M.; COADY, J (Eds.). Second language reading and vocabulary learning. Norwood, NJ: Ablex, 1993. p. 217-228.

GRABE, W.; STOLLER, F. Reading and vocabulary development in a second language. In: COADY, J; HUCKIN, T. Second language vocabulary acquisition. Cambridge: Cambridge University Press, 1997. p. 98-122.

LAUFER, B. The lexical plight in second language reading. In: COADY, J.; HUCKIN, T. (Eds.). Second language vocabulary acquisition. Cambridge: Cambridge University Press, 1997. p. 20-34.

NASSAJI, H. L2 vocabulary learning from context: strategies, knowledge sources, and their relationship with success in L2 lexical inferencing. Tesol Quarterly, v. 37, n. 4, p. 645-670, 2003.

NATION, P; MEARA, P. Vocabulary. In: SCHMITT, N. (Ed.). An introduction to applied linguistics. New York: Oxford University Press, 2000. p. 35-54.

PERFETTI, C. et al. Sources of comprehension failure: theoretical perspectives and case studies. In: CORNOLDI, C.; OAKHILL, J. (Eds.). Reading comprehension difficulties. Mahwah, NJ: L. Erbaum, 1996. p. 137-165.

PERFETTI, C. Reading ability. New York: Oxford University Press, 1985.

STAHL, S. Differential word knowledge and reading comprehension. Journal of Reading Behaviour, v. 15, p. 33-50, 1983. 
306

ANEXO: TEXTO DA REVISTA VEJA

\subsubsection{0 espectadores... ...e subindo: Cidade de Deus, de Fernando Meirelles, é uma combinação rara de prestígio crítico e sucesso popular - ambos merecidos}

1 Com 28 dias de exibição, Cidade de Deus, do diretor Fernando Meirelles, bateu numa marca impressionante: 1,2 milhão de espectadores. Já seria muito se fosse o seu número final. Para termo de comparação, sucessos americanos como Onze Homens e um Segredo têm encerrado sua bilheteria por aqui com 2,5 milhões de ingressos vendidos. Mas Cidade de Deus ainda está longe de fechar suas contas. Num caso raro, sua renda não caiu depois da estréia. Cresceu do primeiro fim de semana para o segundo, e do segundo para o terceiro. As projeções da distribuidora Lumière indicam uma conta final memorável: 2 milhões de espectadores. Mas inédita mesmo é a geografia do sucesso de Cidade de Deus. Boa parte da legião de interessados nessa história de tráfico e sobrevivência na favela vem da periferia das grandes cidades. É nos cinemas de áreas populares - e nos dias de semana, quando o ingresso é mais barato - que o filme tem seu desempenho mais notável. O público 10 comparece em peso, ri, torce, se choca e sai recomendando o programa à vizinhança. Para os defensores da tese de que o cinema é o melhor espelho de um país, Cidade de Deus serve de prova. Fernando Meirelles, porém, não pôde saborear como merecia essa conquista: seu filme já estreou cercado por uma polêmica bizantina.

Segundo uma certa linha de pensamento, filmes como Central do Brasil, Eu Tu Eles e Cidade de Deus seriam exemplos do que a crítica Ivana Bentes escolheu denominar "cosmética da fome". Trata-se de um trocadilho com a expressão "estética da fome", cunhada pelo cineasta Glauber Rocha à época do cinema novo. Num texto recente, Ivana acusa Cidade de ser o auge de um "novo realismo e brutalismo latino-americano". Ela critica a montagem ágil e o virtuosismo da câmera como sintomas de uma ambição sinistra: a de transformar a matança de pobres entre si em espetáculo para consumo. Esse zelo linha-dura envolve duas falácias: a de que um filme sobre uma realidade dramática não pode provocar prazer de nenhum tipo, e a de que o espectador pego pelos sentidos 20 não pensa. Para Walter Salles, produtor do filme, o simples fato de haver tanto debate desmente esse gênero de raciocínio. "O que fez Apocalypse Now, por exemplo, senão elevar à enésima potência um 
conflito absurdo? Cidade de Deus aprofundou a discussão sobre o apartheid social brasileiro e virou matéria urgente, aquilo que o cinema raramente consegue", observa Salles. Parte do tiroteio dirigido contra Cidade de Deus resulta de um preconceito antigo. Sempre que um diretor vem do meio publicitário - caso de Salles, Meirelles e Andrucha Waddington, de Eu Tu Eles -, ele é veladamente acusado de usar seu arsenal de truques para dar um lustro na miséria e faturar com ela. É o tipo de ataque que freqüentemente parece ter algo de maldoso, até porque sugere despeito, e muito de deslocado. Por trás dele, está uma idéia mais do que vencida: a de que, para ser genuíno, um filme brasileiro tem de ser tosco. De tosco Cidade de Deus não tem nada - e de publicitário também não.

30 Apesar dessa minoria ruidosa, Cidade de Deus ganhou um prestígio dentro e fora do Brasil que, na história recente do cinema nacional, só tem antecedentes em Central do Brasil. Adjetivos como "talentoso" ou "genial", no entanto, espantam Meirelles. "Me identifico bem mais com aquele mané que rala para burro há muito tempo", assegura. Em parte, ele diz, Cidade de Deus só saiu porque não sabia muito bem no que estava se metendo. Paulistano de classe média alta, filho de um médico e uma paisagista, o diretor de 47 anos estudou no tradicional Colégio Santa Cruz e tinha pretensões de cursar biologia marinha na França. Chegando lá, constatou que gostava era de praia, não de estudar o oceano, e voltou para fazer arquitetura na Universidade de São Paulo. Nunca levou os croquis adiante: nos anos 80, fundou com alguns amigos a produtora Olhar Eletrônico, cuja cria mais célebre foi o repórter Ernesto Varela - na vida civil, Marcelo Tas. O diretor criou o personagem com Tas e atuava também como o cameraman Valdeci. Com uma família em surgimento para sustentar - ele é "muito bem40 casado" há dezoito anos e tem dois filhos -, Meirelles rumou pouco a pouco para a publicidade. Hoje é sócio de uma das grandes produtoras do país, a O2 Filmes, que entrega as cópias dos comerciais aos clientes em saquinhos de padaria estampados com lemas como "servir bem para servir sempre". Nada na vida pregressa de Meirelles, portanto, poderia prepará-lo para a experiência de Cidade de Deus. "Mal eu pus o pé no morro e já tinha um cara com uma arma apontada para a minha cabeça", conta ele, ressalvando que esse foi um dos poucos episódios de perigo com que sua equipe deparou. "No fim, a filmagem foi o período mais feliz da minha vida. Passei um ano de bermuda e chinelo, cercado de pessoas cheias de entusiasmo", diz. 


\section{8}

A carreira de Meirelles não poderia estar mais em alta. Seu filme é o candidato natural à indicação do Brasil (a ser decidida no fim de outubro) para a disputa pelo Oscar de produção estrangeira. Cidade de Deus já está também vendido para 62 países estrangeiros, e os arquivos de Meirelles na O2 estão recheados de roteiros 50 enviados por estúdios americanos. Entre as várias propostas há uma da Fox, para um filme com Robert De Niro, e outra da Universal, com Tom Hanks à frente do elenco. A primeira ele já recusou, e é possível que a segunda siga o mesmo caminho. Novamente em dupla com Bráulio Mantovani, o roteirista de Cidade de Deus, o diretor está tocando um projeto chamado Intolerância II - em referência ao Intolerância de D.W. Griffith, de 1916, um dos filmes fundadores da cinematografia americana. Enquanto Griffith tratava da história da humanidade através do tempo, porém, Meirelles pretende fazê-lo através da geografia, percorrendo cinco países com seu enredo. "Não estou trocando Hollywood por Intolerância II por esnobismo. Quero fazer um filme lá, porque acho uma experiência necessária", diz Meirelles. "Mas meu agente (o americano John Lesher, o mesmo de Walter Salles) me garantiu que ainda tenho crédito para pisar na bola com os caras umas duas vezes", brinca.

Recebido em 07/02/08. Aprovado em 11/07/08.

Title: Perfetti's knowledge and process categories in L1 reading: an experiment Author: Alessandra Baldo

Abstract: Perfetti et al. (1996) classify the components of reading comprehension into two main categories: process and knowledge categories. While lexical processes, working memory capacity, inference making and comprehension monitoring are situated in the first one, word knowledge and domain knowledge are placed in the second one. This paper aims at showing the relevance of the types of knowledge that make up the second category to the overall reading comprehension process, as well as the interdependence between both categories. In order to do so, a comparison was made between the strategies used by eight adult readers while answering specific questions related to vocabulary inference as part of an L1 reading test carried out through the verbal protocol technique. Participants were divided into two groups of reading proficiency, according to their scores on the test. Data analysis ratified the intrinsic relationship between word meanings and domain knowledge on reading comprehension processes, more specifically on lexical inferencing.

Keywords: knowledge; comprehension; reading strategy; word meaning; lexical inferencing.

Titre: Les catégories connaissance et procès de Perfetti dans la lecture en langue maternelle: un essai

BALDO - As categorias conhecimento e... 
Auteur: Alessandra Baldo

Résumé: Perfetti et al. (1996) partagent en deux catégories les composants présents dans la compréhension de la lecture: celle de procès et celle de connaissance. Dans la première, il y a les procès lexicaux, la capacité de la mémoire de travail, l'accomplissement d'inférences et le contrôle de la compréhension; dans la deuxième, le sens des mots et la connaissance de domaine. Cet article a comme objectif démontrer l'importance des types de connaissance impliqués dans la deuxième catégorie pour le procès global de compréhension de la lecture, et aussi l'interdépendance entre les deux catégories. Pour autant, on a réalisé une comparaison entre les stratégies utilisées par huit lecteurs adultes qui ont répondu à des questions spécifiques d'inférence de vocabulaire, à partir de l'emploi d'un test de compréhension de lecture en langue maternelle par la technique des protocoles verbaux. En s'appuyant dans les scores obtenus, les participants ont été partagés en deux groupes distincts de compétence en lecture. L'analyse a aidé à confirmer l'intrinsèque rapport entre signification de mots et connaissance de domaine dans des procès de compréhension de la lecture, surtout d'inférence lexicale.

Mots-clés: compréhension; stratégie de lecture; connaissance; signification de mots; inférence lexicale.

Título: Las categorías conocimiento y procesos de Perfetti en la lectura en lengua materna: un experimento

Autor: Alessandra Baldo

Resumen: Perfetti et al. (1996) dividen en dos grandes categorías los componentes presentes en la comprensión lectora: la de procesos y la de conocimiento. En la primera, están los procesos lexicales, la capacidad de la memoria de trabajo, la realización de inferencias y el monitoramiento de la comprensión; en la segunda, el significado de las palabras y el conocimiento de dominio. El presente artículo tiene como objetivos mostrar la importancia de los tipos de conocimiento implicados en la segunda categoría para el proceso global de comprensión lectora, como también la interdependencia entre las dos categorías. Para tanto, fue realizada una comparación entre las estrategias utilizadas por ocho lectores adultos al responder las cuestiones específicas de inferencia de vocabulario, a partir de la aplicación de una prueba de comprensión lectora en lengua materna por la técnica de los protocolos verbales. Con base en los puntajes obtenidos, los participantes fueron divididos en dos grupos distintos de proficiencia en lectura. El análisis vino a corroborar la intrínseca relación entre significado de palabras y conocimiento de dominio en los procesos de comprensión lectora, en especial de inferencia lexical.

Palabras-clave: comprensión; estrategia de lectura; conocimiento; significado de palabra; inferencia lexical. 